\title{
DEVELOPMENT WEB APPLICATION FOR ENHANCING INFORMATION AND ACTIVITY IN RPTRA MAYA ASRI 13
}

\author{
Yulyani ARIFIN ${ }^{* *}$, Elizabeth Paskalia GUNAWAN ${ }^{2}$ and Margaretha OHYVER ${ }^{3}$ \\ ${ }^{1,2}$ Computer Science Department, School of Computer Science, Bina Nusantara University, Jakarta, Indonesia \\ ${ }^{3}$ Statistics Department, School of Computer Science, Bina Nusantara University, Jakarta, Indonesia \\ "yulyaniarifin@binus.ac.id
}

\begin{abstract}
RPTRA is a gathering place for children and other residents to socialize physically. The children can play at RPTRA. However, due to the COVID-19 pandemic which causes physical activity restrictions, this is an obstacle for RPTRA. Due too physical distancing and social distancing, no one can visit RPTRA. So, The RPTRA must be transformed if they want to be sustain and growth in the future. In addition, in order for the RPTRA to develop, digital transformation is also needed in the development of the RPTRA. Based on related research, digital transformation is needed for community to growing in the future. Through a research methodology that starts from collecting data through Contextual Inquiry, then it is analyzed and produces a system design using UML and user interface design using Figma. Furthermore, it is developed into a website application. This website application is evaluated through System Usability Scale (SUS) and heuristic evaluation. The evaluation results show that the proposed application has an SUS value above the average. We can conclude through this website application can be used for sharing information inside the community also can engage with the society. In the future, it is hoped that this RPTRA website application apart from being an information suggestion can also be used to market the products of RPTRA itself so that it can add to the economic value of this website.
\end{abstract}

Keywords: RPTRA, Website, Information, SUS

\section{BACKGROUND}

Ruang Publik Terpadu Ramah Anak (RPTRA) is a product of the DKI Jakarta government from 2015 to 2019. Currently, there are 296 RPTRAs that have been built based on the DKI Jakarta government budget and also funds from Corporate Social Responsibility (CSR) (1). The function of the RPTRA is as an open public facility, a vehicle for games and children's development, a means for residents to socialize, develop skills and knowledge of local residents as well as green space facilities (2). Given the importance of the role of this RPTRA, the government is very concerned about the preparation and design of the place for this RPTRA (3). The results of the research of T. Herry Rachmatsyah and Chicilia showed that the role of the RPTRA was very effective in the RPTRA Kenangan area (4). In other areas such as Makassar, there are also places like this RPTRA which provide a useful role for children around Losari Beach (5).

Activities that are not essential have had to be temporarily suspended due to the Covid-19 pandemic that has hit the world. Many impacts have been felt since the COVID-19 pandemic increased. From the research conducted by Singh et al that examined the impact of COVID-19, one of which was on the economic impact, world stock values began to fall (6). This impact is also felt in Indonesia, especially DKI Jakarta. Since the Covid-19 pandemic hit, especially now the number of Covid-19 sufferers is increasing and macro-scale restrictions are being carried out in the DKI Jakarta area. Many activities that have begun to be postponed, including activities at the RPTRA have also been temporarily suspended. Many activities began to be directed through online activities. RPTRA Maya Asri 13 is also one of the places that is temporarily closed so that physical arrivals cannot be made by residents. One of the actions taken in dealing with the Implementation of Community Activity Restrictions known as Pemberlakuan Pembatasan Kegiatan Masyarakat (PPKM) is to provide tutorial learning videos that can be accessed by students who usually come directly to RPTRA MAYA ASRI 13. From the results of previous research, it shows that there is a positive influence and children can better understand learning materials through video-based learning (7). Learning activities can be resolved through learning videos, but there are not too many interested people who came physically before the pandemic, only known by some residents who live around the RPTRA.

According to Plunkett et al, a community can develop because of the deep involvement of various parties in the community and the social capacity of the community needs to be improved and strengthened (8). RPTRA Maya Asri 13 needs to build community capacity to be stronger and can provide a means that can bring people together to get involved. The crisis caused by the Covid-19 pandemic has caused a change from a traditional citizen to a digital citizen. Buchholz et al said the crisis from Covid-19 provided an opportunity to improve the digital capabilities of the community in order to adapt to social distancing and physical distancing conditions (9) (10).

In today's digital era, digital literacy skills are needed. Organizations or communities need to carry out digital transformation in order to improve the digital capabilities needed today in order to survive and thrive in the future (11). Digital transformation from a social perspective aims to accelerate the development of a more innovative and collaborative culture in industry and society as well as improve the accessibility and quality of digital services offered to the community (12). In digital transformation, a multidisciplinary approach is also needed in solving the problems encountered (13). In the current education period, there have been many educations at the elementary 
to university level that emphasize the use of digital literacy in the world of education to prepare students to have the digital literacy skills needed in the current era of digital transformation (14).

RPTRA Maya Asri 13 needs to keep up with the times and be able to face the crisis caused by COVID-19 by participating in digital transformation. Currently, there is no application facility that allows the activities or information carried out by RPTRA Maya Asri 13 to be known by the public. Website platform development can help increase engagement in a community. As done by Shah et al, who developed a website-based event management platform to increase collaboration and engagement in the desired community (15). Piatkowski et al concluded that the website can help the cycling community to gather information quickly (16). The Coronapp website can help collect information regarding the Corona virus and its mutations (17). Various research results related to the use of web-based applications have become the basis for developing a platform for RPTRA Maya Asri 13 to be able to increase the dissemination of information and activities related to RPTRA and can be used to increase engagement within the RPTRA community through proposed websitebased application development.

Through the development of this website application, it can also be used to improve the digital literacy of the RPTRA administrators. The method used in this study was started from a group discussion forum with RPTRA administrators then analyzed and developed a websitebased application. Furthermore, usability evaluation was carried out to determine the usability level of the proposed application (18) and evaluation based on heuristics to measure the suitability of the interface design with the established standard (19).

\section{METHOD}

The research methodology consists of several stages, namely:

1. Data Collection Stage

At this stage, a Contextual Inquiry was conducted with the RPTRAadministrators. The discussion forums were conducted more specifically to find out the obstacles or needs needed by the RPTRA administrators.

2. Analysis Stage

At this stage an analysis of the results of the Contextual Inquiry is carried out. Based on the logging obtained during the results of the Discussion forum, the data were analyzed quantitatively and qualitatively.

3. Design Stage

The design is carried out starting from a system design using Use Case Diagrams and Activity Diagrams. Then for the interface design using Figma. At this design stage, an evaluation is carried out first on the RPTRA Management to find out whether the design is in accordance with the needs or if there is something that needs to be added further.

\section{Application Development Stage}

Application development consists of making front end and back end with PHP Laravel programming language which is commonly used in website development.

5. Evaluation Stage

The evaluation is carried out based on the usability level of the application using the SUS Questionnaire (20) and heuristic evaluation based on guidance from Jacobs Neilsen (21).

\section{RESULT AND DISCUSSION}

From the results of the design stage, it can be seen that the design functionality of the proposed website application through the use case diagram (Figure 1). The use case diagram consists of two actors, namely visitors and admins.

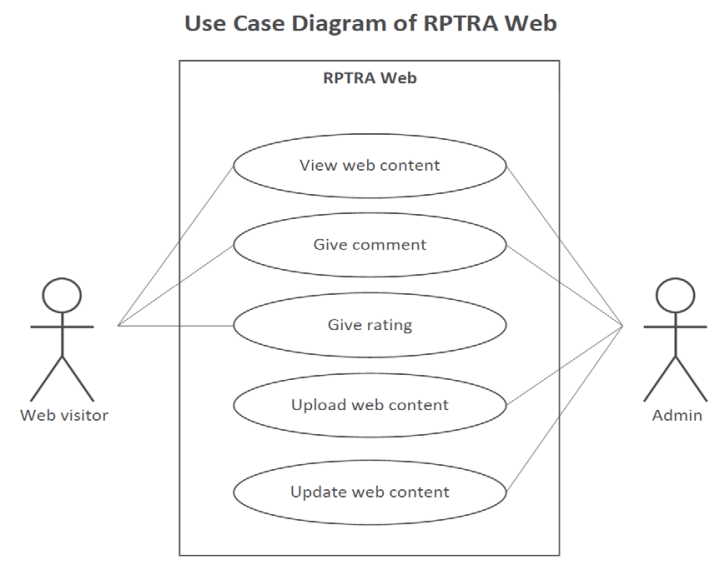

Figure 1 Use Case Diagram of RPTRA Website.

The RPTRA website application (figure 2) consists of several features, namely the homepage feature which consists of the history, organizational structure, and job descriptions of each unit, the article feature which can be a means of sharing knowledge and skills or also other important information, the activity documentation feature in the form of photos and videos. Videos of RPTRA activities and our contact feature can be used by the public if anyone wants to ask questions or give suggestions.

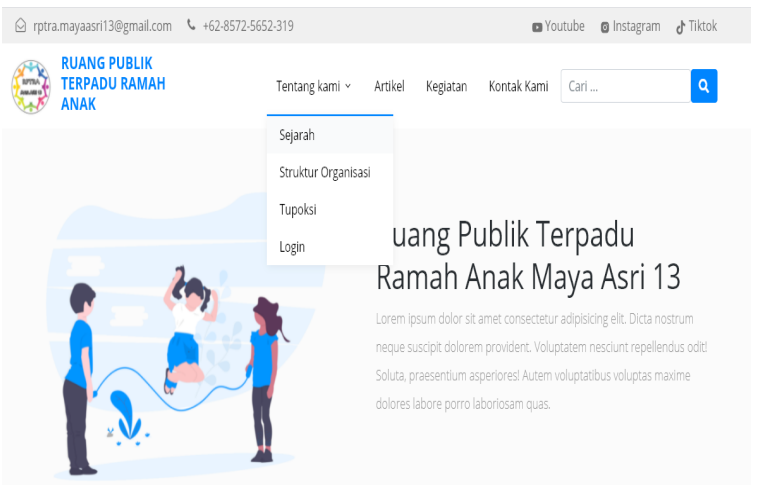

Figure 2 Feature Design About Us

Beside the feature of about us, activity and contact us, the visitor can see the article that provided in this web. Through the feature article, it can involve contributions from the community, visitors can provide comments or 
provide feedback on the articles provided. This feature can be seen in Figure 3.

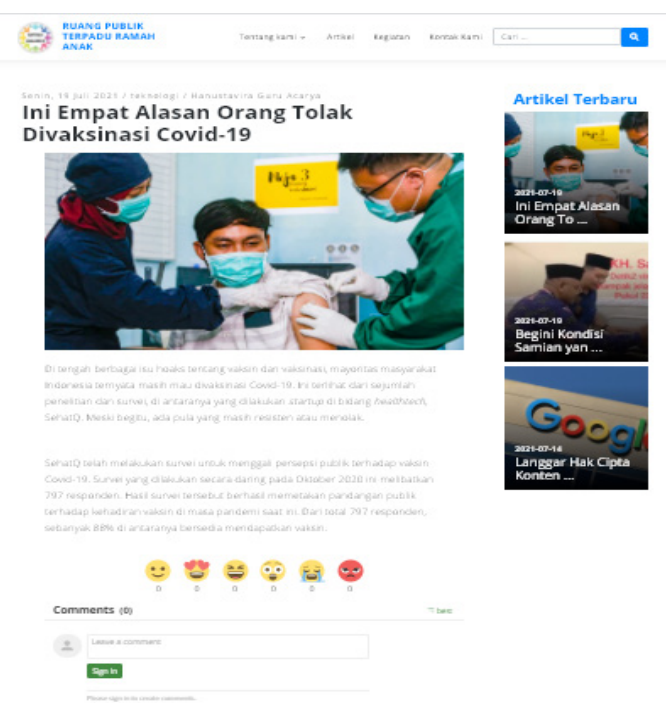

Figure 3 Article Feature Design

The evaluation stage is carried out with the RPTRA administrators. RPTRA administrators conduct tests on the RPTRA website application from the visitor side and the admin side. Every feature is tested by this RPTRA Administrator. Then after doing the test, the RPTRA management filled out a questionnaire that had been designed to follow the SUS Questioannaire. The 10 questions from the SUS Questionnaire can be seen in Table 1 as follows

\section{Table 1 Questioannaire questions}

Q1 I think I can use this website application regularly
Q2 This RPTRA Website Application is simple
Q3 RPTRA Website Application is easy to use
Q4 I think I need a trainer to accompany me when using this
RPTRA Website application
Q5 I found the features in the RPTRA Website application
running well
Q6 I think the interface design is too much inconsistent
Q7 I imagine many people will find it easy to learn this
Q8 I I find this RPTRA Website application difficult to use
Q9 I feel confident using this RPTRA Website application
Q10 I need to learn many things in order to use this RPTRA

From the results of the evaluation, the average SUS of the respondents was 95.62. This shows the SUS value if it exceeds 68 , then the RPTRA website application has good usability. Based on the results of the questionnaire regarding whether the RPTRA website can improve user accessibility and increase the dissemination of information related to RPTRA activities, $100 \%$ of the respondents agreed with this. Based on this evaluation, it can be concluded that the RPTRA Website application can help the public to find out information related to RPTRA through digitalization facilities and this RPTRA website application is in accordance with user needs both in terms of efficiency, effectiveness and user satisfaction based on the SUS value obtained from the evaluation results.

If the interface design is evaluated based on the heuristic evaluation from Jacob Neilsens (22) then in terms of visibility of system status, there is always feedback every time the user makes comments or interacts with the RPTRA website, then from the suitability between the system and the real world it can be seen from the icon or The menu used is commonly found in everyday life such as the search button. Regarding user control and freedom, users can freely choose the desired menu without having to start from the first feature. In terms of consistency and standards, it can be seen in the design of the menu features, the colors are all the same for each feature. Regarding error prevention, the Admin menu has provided a date format so that the admin when adding data will not be wrong in writing the date format. Users are also facilitated with a commonly used interface design so that the first time you use it, you can still easily get the information you want. In terms of flexibility and efficiency of use, it can be seen in the expand menu design where the user is shown only part of the information, but if the user wants to see more details, just select the expand menu. The aesthetic and minimalist side can be seen in the display of existing activity photos and videos, the distribution is done per paging so that users only see part by part so it is more minimalist. If the user has made a mistake in selecting the menu, the user can select the homepage so that they can return to their original position. In the last rule, namely the help and documentation menus, our contact feature is currently only available, so if there is something that users want to ask, they can contact the admin through our contact feature. From the results of the heuristic evaluation, it can be concluded that the interface design of the RPTRA Website application has a good interface design and is easy to use by users.

\section{CONCLUSION}

This RPTRA website application can help RPTRA administrators in introducing this RPTRA Maya ASRI 13 to the wider community. Through this website application, it is also possible to increase the digital literacy of RPTRA administrators so that they can help develop RPTRA and survive during this COVID-19 pandemic.

From the results of the evaluation based on usability which has a SUS (System Usability Scale) value which is 95 above the standard value of 68 , this shows that this RPTRA Website application has good usability. Then the results of the heuristic evaluation also show that the interface design of this website application is good and easy to use.

For further research, if the website is developed further by displaying the products of the RPTRA, the impact of the website can be analyzed not only as a means of information but also as an economic means for the RPTRA itself. 


\section{REFERENCES}

1. Iqsyan Iswara Putra. https://statistik.jakarta.go.id/ jumlah-ruang-publik-terpadu-ramah-anak-rptrayang-diresmikan-pemprov-dki-jakarta-hinggatahun-2019/. Dinas Pemberdayaan Perlindungan Anak dan Pengendalian Penduduk DKI Jakarta. 2019.

2. Ruang Publik Terpadu RamahAnak(RPTRA) [Internet]. DKI Jakarta. [cited 2021 Jul 19]. Available from: https://dprkp.jakarta.go.id/?cmd=product-rptra

3. Derr V, Tarantini E. "Because we are all people": outcomes and reflections from young people's participation in the planning and design of child-friendly public spaces. Local Environ. 2016;21(12):1534-56.

4. Herry Rachmatsyah T, Chicilia. Study of Effectiveness of Integrated Public Space. IOP Conf Ser Mater Sci Eng. 2020;924(1).

5. Ali M, Aliah SE, Fachrul R, Musdalifah. Identification of Child-Friendly Integrated Public Spaces in Makassar City (Case Study: Losari Beach). IOP Conf Ser Mater Sci Eng. 2020;875(1).

6. Onyema EM. Impact of Coronavirus Pandemic on Education. J Educ Pract. 2020;11(13):108-21.

7. Arifin Y, Permai S, Syahchari H, Raharto A. ANALYSIS OF THE RELATIONSHIP OF THE LEARNING VIDEO WITH STUDENTS 'UNDERSTANDING OF LEARNING MATERIALS. 2018;1-6.

8. Plunkett D, Phillips R, Ucar Kocaoglu B. Place Attachment and Community Development. J Community Pract [Internet]. 2018;26(4):471-82. Available from: https://doi.org/10.1080/10705422. 2018.1521352

9. BuchholzBA, DeHartJ, Moorman G. Digital Citizenship During a Global Pandemic: Moving Beyond Digital Literacy. J Adolesc Adult Lit. 2020;64(1):11-7.

10. Fletcher G, Griffiths M. Digital transformation during a lockdown. Int J Inf Manage [Internet]. 2020;55(June):102185. Available from: https://doi. org/10.1016/j.ijinfomgt.2020.102185

11. Sousa MJ, Rocha Á. Digital learning: Developing skills for digital transformation of organizations. Futur Gener Comput Syst [Internet]. 2019;91:32734. Available from: https://doi.org/10.1016/j. future.2018.08.048
12. Ebert C, Duarte CHC. Digital Transformation. IEEE Softw. 2018;35(4):16-21.

13. Verhoef PC, Broekhuizen T, Bart Y, Bhattacharya A, Qi Dong J, Fabian N, et al. Digital transformation: A multidisciplinary reflection and research agenda. J Bus Res. 2021;122(September):889-901.

14. McDougall J, Readman M, Wilkinson P. The uses of (digital) literacy. Learn Media Technol [Internet]. 2018;43(3):263-79. Available from: https://doi.org/ 10.1080/17439884.2018.1462206

15. Shah A, Abhishek DM, Aneesh R, Aishwarya SR, Taj T. Community web application for event management platform. Int J Progress Res Sci Eng. 2020;1(5):116-20.

16. Piatkowski D, Marshall W, Afzalan N. Can web-based community engagement inform equitable planning outcomes? A case study of bikesharing. J Urban [Internet]. 2017;10(3):296-309. Available from: http://dx.doi.org/10.1080/17549175.2016.1254672

17. Mercatelli D, Triboli L, Fornasari E, Ray F, Giorgi FM. Coronapp: A web application to annotate and monitor SARS-CoV-2 mutations. J Med Virol. 2021;93(5):3238-45.

18. Hendra SK, Yulyani Arifin SK. Web-based Usability Measurement for Student Grading Information System. Procedia Comput Sci [Internet]. 2018;135:238-47. Available from: https://doi. org/10.1016/j.procs.2018.08.171

19. Iannella R. Heuristic User Interface Evaluation : Three Case Studies of Dialog Design. (1991).

20. Matera M, Rizzo F, Carughi GT. Web usability and accessibility 5 Web Usability: Principles. J Web Eng. 2008;4(7):257-257.

21. Väänänen-Vainio-Mattila K, Wäljas M. Evaluating user experience of cross-platform web services with a heuristic evaluation method. Int $\mathrm{J}$ Arts Technol [Internet]. 2010;3(4):402. Available from: http://www.scopus.com/inward/record.url?eid=2s2.0-84858813675\&partnerID $=40 \& \mathrm{md} 5=1 \mathrm{fb} 7$ cd18d74d0dfc83b941ba7cdfceb6\%5Cnhttp:// www.scopus.com/inward/record.url?eid=2-s2.084858813675\&partnerID=tZOtx3y1

22. Nieilsen J. No Title [Internet]. 2020 [cited 2021 Jul 19]. Available from: https://www.nngroup.com/ articles/ten-usability-heuristics/ 